\title{
Selective Laser Melting of Ti6Al4V sub-millimetric cellular structures: Prediction of dimensional deviations and mechanical performance
}

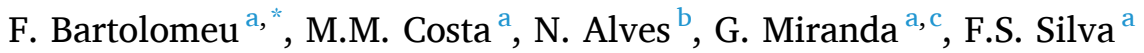 \\ ${ }^{\text {a }}$ Center for Micro-Electro Mechanical Systems (CMEMS-UMinho), University of Minho, Campus de Azurém, 4800-058, Guimarães, Portugal \\ ${ }^{\mathrm{b}}$ Centre for Rapid and Sustainable Product Development Polytechnic Institute of Leiria, Rua General Norton de Matos, Apartado 4133, 2411-901, Leiria, Portugal

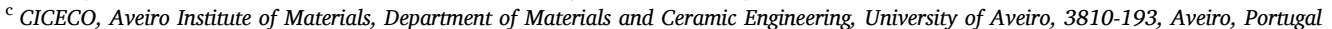

\section{A R T I C L E I N F O}

\section{Keywords:}

Selective laser melting

Ti6Al4V

Cellular structures

Design tools

Elastic modulus

\begin{abstract}
A B S T R A C T
Ti6Al4V sub-millimetric cellular structures arise as promising solutions concerning the progress of conventional orthopedic implants due to its ability to address a combination of mechanical, physical and topological properties. Such ability can improve the interaction between implant materials and surrounding bone leading to longterm successful orthopedic implants. Selective Laser Melting (SLM) capability to produce high quality Ti6Al4V porous implants is in great demand towards orthopedic biomaterials. In this study, Ti6Al4V cellular structures were designed, modeled, SLM produced and characterized targeting orthopedic implants. For that purpose, a set of tools is proposed to overcome SLM limited accuracy to produce porous biomaterials with desired dimensions and mechanical properties. Morphological analyses were performed to evaluate the dimensional deviations noticed between the model CAD and the SLM produced structures. Tensile tests were carried out to estimate the elastic modulus of the Ti6Al4V cellular structures. The present work proposes a design methodology showing the linear correlations found for the dimensions, the porosity and the elastic modulus when comparing the model CAD designs with Ti6Al4V structures by SLM.
\end{abstract}

\section{Introduction}

Metallic biomaterials such as stainless steel, CoCr alloys, Ti and Ti6Al4V have been extensively used as orthopedic biomaterials. Ti6Al4V alloy has drawn increasing attention owing to its excellent mechanical and biological performance and also corrosion resistance (Moura et al., 2019, 2020). When considering metallic implants, the elastic modulus is one of the most crucial parameters in terms of mechanical performance (Ataee et al., 2018; Weißmann et al., 2016). Despite the elastic modulus of Ti6Al4V $(\approx 110 \mathrm{GPa})$ being lower than that of stainless steel and cobalt-based alloys ( $\geq 200 \mathrm{GPa}$ ), it is significantly higher when compared to human cortical bone tissue (ranging from 10 to $30 \mathrm{GPa}$, being influenced by gender, age, among other) (Chen et al., 2017; Fousová et al., 2017; Bose et al., 2018; Capek et al., 2016). A non-adequate stress distribution in the bone-implant interface (stress shielding) occurs due to the mismatch existing between the implant material and the bone tissue (Ryan et al., 2006; Wally et al., 2019). When analyzing the performance of conventional hip implants, this phenomenon has led to unavoidable and progressive bone resorption around the implant until reaching a critical moment (usually 10-20 years after total hip arthroplasty surgery) when revision surgery is needed (Holzwarth and Cotogno, 2012; Bartolomeu et al., 2018a; Wittenberg et al., 2013).

Porous biomaterials have been recognized as an effective solution to lower the elastic modulus mismatch currently found on dense Ti6Al4V implants produced by conventional processing routes (Ryan et al., 2006; Bobbert et al., 2017; Bartolomeu et al., 2019a; Buciumeanu et al., 2018; Huang et al., 2020). In fact, Ti6Al4V porous biomaterials are in great demand due to these materials capability to address several requirements in a single component by fitting, simultaneously, the mechanical, physical and biological properties, which have potential to be patient-customized (Wang et al., 2016; Van Hooreweder et al., 2017; Bartolomeu et al., 2018b). In this sense, when designing Ti6Al4V cellular structured materials targeting orthopedics, several mechanical requirements have to assured, such as the strength, the fatigue resistance and particularly, the stiffness (Wei $\beta$ mann et al., 2016; Bartolomeu et al., 2017a; Tong et al., 2016). The design of materials for implants can be carried out considering the specific anatomical location and the patient, with precise information obtained by tomography or magnetic resonance imaging 3D data (tibia, knee and hip) (Ryan et al., 2006; Chen and

\footnotetext{
* Corresponding author.

E-mail address: flaviojorgebartolomeu@gmail.com (F. Bartolomeu).
} 
Thouas, 2015; Yan et al., 2015; Thavornyutikarn et al., 2014).

Selective Laser Melting (SLM) is an additive manufacturing powder bed fusion process able to fabricate 3D components based on CAD data. Being a layer-wise technique, by using SLM, engineers can design complex and customized solutions with a high design freedom (Wang et al., 2016; Van Hooreweder et al., 2017; Cai et al., 2018). SLM versatility allows the production of porous structures, which are almost impossible or unprofitable to consider when using conventional processing routes such as casting and forging (Buciumeanu et al., 2018; Bartolomeu et al., 2017a). However, the accuracy of SLM technique for the production of sub-millimetric cellular structured biomaterials is typically limited, once noteworthy differences are usually found when comparing CAD model design with the SLM produced components (Bagheri et al., 2017; Yan et al., 2012). M. Dallago et al. (2019a) report the importance of considering the limitations in accuracy of SLM manufacturing technique due to strut oversize, waviness and roughness when designing load bearing lattice structures. Studying these differences can be challenging once there is a large number of processing parameters that in some extension can influence the final accuracy of the part (Sing et al., 2018). These differences are critical when considering SLM technique to fabricate materials with specific geometries and porosities targeting near-net-shape solutions and rigorous mechanical behavior such as the material stiffness (Wang et al., 2016; Bagheri et al., 2017; Dias et al., 2014). In fact, design tools to help obtaining porous structures with desired physical and mechanical properties are a current critical need when considering the use of SLM technology.

In the present study, Ti6Al4V cubic-like structures with five different levels of porosity were designed, SLM fabricated and characterized targeting orthopedic implants and physical, morphological and mechanical characterizations were carried out. Moreover, design tools are proposed for the fabrication of Ti6Al4V cubic-like structures that display the intended dimensions, porosity and mechanical properties by SLM.

\section{Materials and methods}

\subsection{Material and SLM fabrication details}

Ti6Al4V powder (D90 of $40 \mu \mathrm{m}$ ) from SLM Solutions ${ }^{\circledR}$ (Germany) was used to fabricate Ti6Al4V cubic-like structures. Fig. 1 shows a SEM image with the morphology of the powder.

SLM fabrication route starts with a CAD design and through a layerwise fabrication proceeds till obtaining a final component (see Fig. 2).

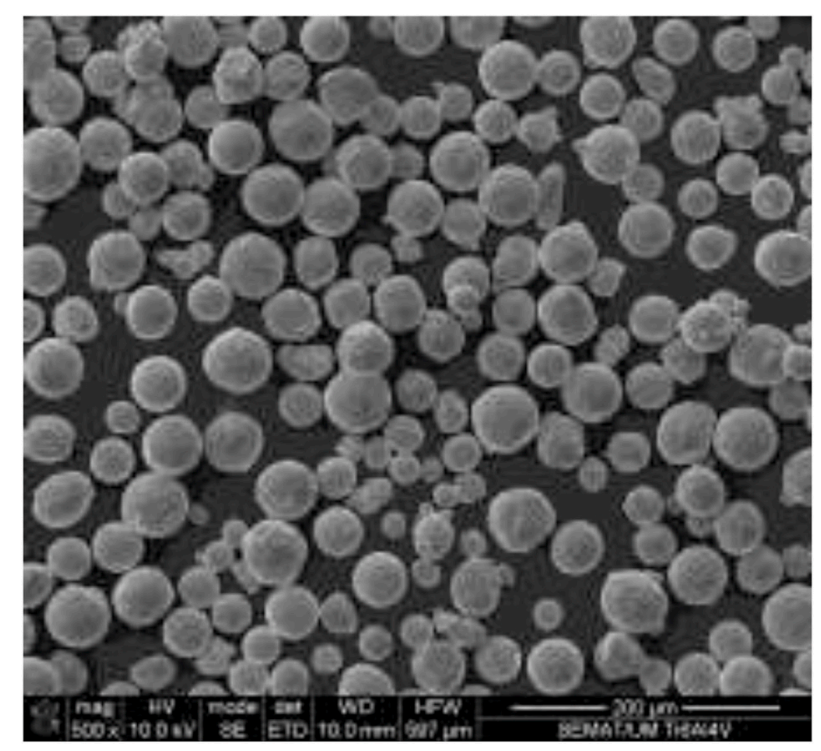

Fig. 1. SEM image of Ti6Al4V powder.
The processing parameters used in this work were defined through an optimization study regarding the processing parameters for Ti6Al4V, using this SLM equipment (Bartolomeu et al., 2016). Accordingly, laser power $(90 \mathrm{~W})$, scan speed $(600 \mathrm{~mm} / \mathrm{s})$, scan spacing $(90 \mu \mathrm{m})$ and layer thickness $(30 \mu \mathrm{m})$ were used, corresponding to a density of energy of $55.6 \mathrm{~J} / \mathrm{mm}^{3}$.

\subsection{Design of Ti6Al4V structures}

When designing cellular structures to integrate in orthopedic implants several issues must be considered in order to mimic some of the key natural bone properties and in this way improve the osteointegration of the implant (Arabnejad et al., 2016; Karageorgiou and Kaplan, 2005; Kumar et al., 2016). Some of these aspects are open-cell size, wall size (distance between two consecutive open-cells), open-cell morphology, orientation and interconnectivity and the surface area to volume ratio.

Table 1 shows the model CAD design details of the cubic-like Ti6Al4V cellular structures investigated in this study. Structures with wall sizes equal or higher than $100 \mu \mathrm{m}$ and open-cell sizes from 500 to $600 \mu \mathrm{m}$ were designed, resulting in CAD porosities between 64.2 and 93.3\%.

\subsection{Morphology analysis and porosity measurements}

After SLM fabrication, SEM images of the Ti6Al4V structures were acquired and used to measure the open-cell and wall dimensions. Further details about the morphological characterization can be found elsewhere (Bartolomeu et al., 2020a). A total of 30 measurements (frontal and lateral planes) were carried out for each structure typology (SP1, SP2, SP3, SP4 and SP5). The average open-cell and walls (distance between two consecutives open-cells) sizes were obtained and then used to model new CADs, hereafter named as adjusted CADs. These new designs (adjusted CADs) intended to reproduce the real dimensions of the SLM produced structures, allowing to carry out finite element simulations and comparing with the experimental tensile results. Three specimens for each condition of the Ti6Al4V specimens were used for accessing the porosity by measuring the mass and volume and considering the theoretical density of Ti6Al4V.

\subsection{Mechanical testing and mechanical modeling}

Tensile tests were conducted using a universal servo hydraulic testing equipment (Instron 8874, USA) at room temperature. The load gauge of the equipment was used for the load signal acquisition and the tests were performed with a crosshead speed of $0.005 \mathrm{~mm} / \mathrm{s}$. The strain signal was obtained using a dynamic extensometer from Instron (model 2620-601) which was designed according to ISO 9513 standard. After testing, stress-strain plots were prepared and the elastic modulus was obtained using the slope of the linear elastic regime. Fig. 3 shows some details of the experimental apparatus used to perform the tensile tests.

Finite element analyses (FEA) were carried out for comparison purposes with the experimental tensile tests. Simplified models were considered for each structure typology and finite element meshes were generated using tetrahedral elements. The material of the structures was defined as linear elastic, Ti6Al4V with an elastic modulus of $110 \mathrm{GPa}$, a Poisson's ratio of 0.30 and density of $4500 \mathrm{~kg} / \mathrm{m}^{3}$ (Chen and Thouas, 2015; Rotta and Seramak, 2015). A load (F) was applied on the upper surface of the model and the elastic modulus (E) was estimated using the following expression:

$E_{f}=\frac{F}{A} \times \frac{L_{0}}{\Delta L}$

where $A$ is the initial area of the structure, and the axial strain, $\varepsilon=$ $\left(\frac{\Delta L}{L_{0}}\right)$. 


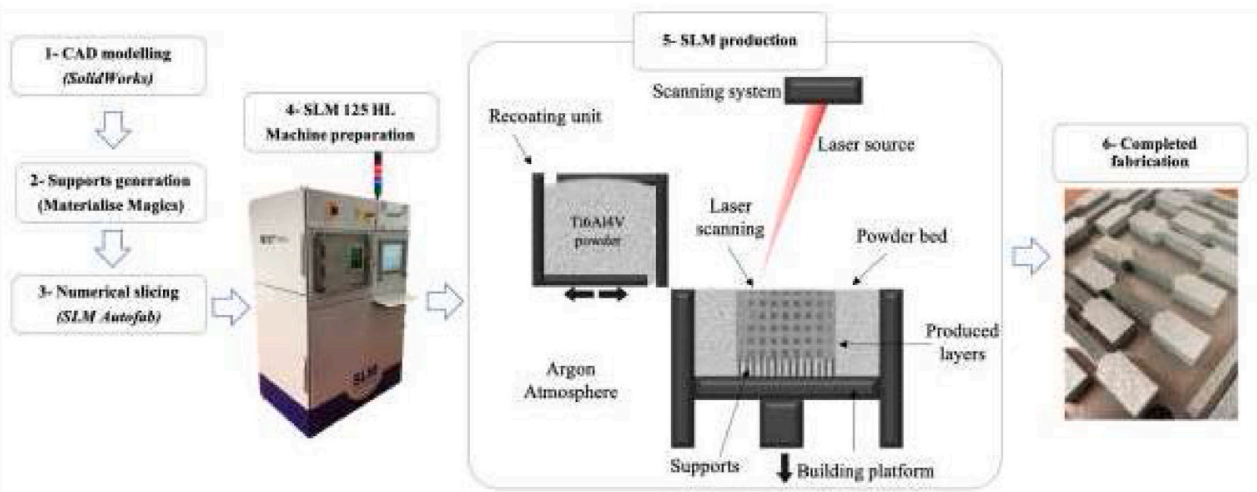

Fig. 2. Schematic representation of SLM technique, from CAD data to final component.

Table 1

Model CAD design details for the tested specimens.

\begin{tabular}{llll}
\hline Structure nomenclature & \multicolumn{3}{l}{ Model CAD design details } \\
\cline { 2 - 4 } & Open-cell size $(\mu \mathrm{m})$ & Wall size $(\mu \mathrm{m})$ & Porosity $(\%)$ \\
\hline SP1 & 500 & 300 & 64.2 \\
SP2 & 600 & 300 & 70.3 \\
SP3 & 500 & 150 & 84.0 \\
SP4 & 600 & 150 & 87.6 \\
SP5 & 600 & 100 & 93.3 \\
\hline
\end{tabular}

Fig. 4 shows the geometrical models and aims to highlight the numerical analyzes details, the boundary conditions and the typical refined mesh used in the FE analysis. Fig. 4 (a)-(d) shows the defined boundary conditions: (a) boundary load; (b) prescribed displacement $\left(\mathrm{u}_{0 \mathrm{x}}=0\right)$; (c) prescribed displacement $\left(\mathrm{u}_{0 \mathrm{z}}=0\right)$; (d) prescribed displacement $\left(\mathrm{u}_{0 \mathrm{y}}=\right.$ 0 ). Mesh converge analysis was carried out through a parametric study aiming to assure the convergence and accuracy of the numerical results.

\section{Results and discussion}

\subsection{Morphological characterization of the SLM structures}

SLM technique was used to fabricate five Ti6Al4V dog-bone specimens that are cubic-like structured in the reduced section length. Fig. 5 (a) shows the SLM platform after production and excess powder removal, Fig. 5 (b) displays the produced specimens after being removed from the platform and Fig. 5 (c) shows isometric SEM images of SP3 and SP5.

SEM images of the front and lateral planes (polished) of each structure were obtained and later used to perform a morphological investigation in which the average sizes of the open-cell and wall were estimated. As an example, Fig. 6 shows the CAD design and also SEM images of the as-produced and polished SP5 structure. In Table 2 can be seen, for all the structures (SP1 to SP5), the obtained average sizes when compared with the initial model CAD dimensions and also the porosity.

When analyzing the results of Table 2 and the example displayed in Fig. 6, it is possible to understand that systematic deviations are found when comparing the model CAD and the structures produced by SLM. Considering the five types of structures (SP1 to SP5), on average, the open-cell sizes are $\approx 105 \mu \mathrm{m}$ lower and the wall sizes are $\approx 99 \mu \mathrm{m}$ higher comparing to the model CAD dimensions. In fact, it is important to highlight that these deviations were found for all the investigated structures indicating that these dissimilarities are inherent to SLM technique, as reported in several studies (Arabnejad et al., 2016; Bartolomeu et al., 2017b, 2019b, 2020a; Ran et al., 2018). In literature several studies can be found indicating that the fabrication of sub-millimetric porous structures by SLM leads to $\approx 100 \mu \mathrm{m}$ smaller open-cells and $\approx 100 \mu \mathrm{m}$ thicker walls (Bagheri et al., 2017; Yan et al., 2012; Arabnejad et al., 2016; Dallago et al., 2019b). One relevant aspect related with this behavior is the partially melting of some powder in the vicinity of the laser melted zones, event that leads to an increase on the thickness of the walls and consequent decrease of the open-cells dimensions (Van Bael et al., 2011). Moreover, powder sticking to the solid surface due to the differences in heat transport between powder material and solid material also occurs (Ran et al., 2018). These deviations between the designed and the produced structures are not negligible and are particularly crucial for orthopedic implants where these structures are fabricated aiming to exhibit specific morphological, physical and mechanical properties that dictate the resulting biological outcome.

Fig. 7 shows the linear correlation between the porosity of the SLM fabricated Ti6Al4V structures and the CAD model porosity, with a coefficient of determination of $98.2 \%$. Fig. 8 shows the linear correlations between the measured open-cell and wall sizes, and the corresponding
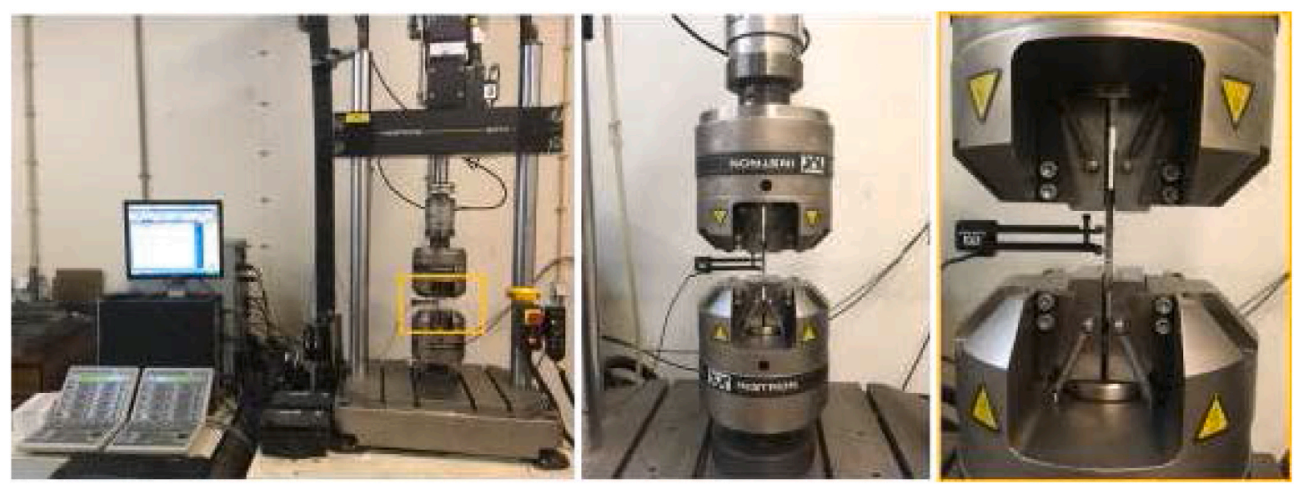

Fig. 3. Mechanical testing system used to perform the tensile tests. 


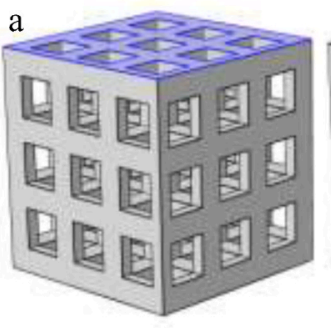

b $20=0$

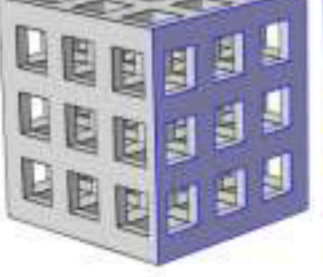

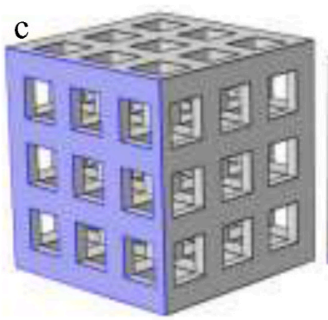

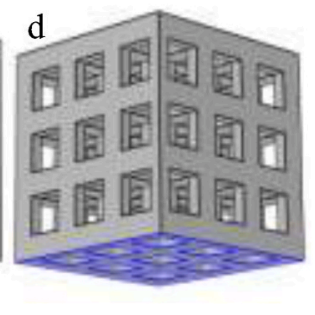

e
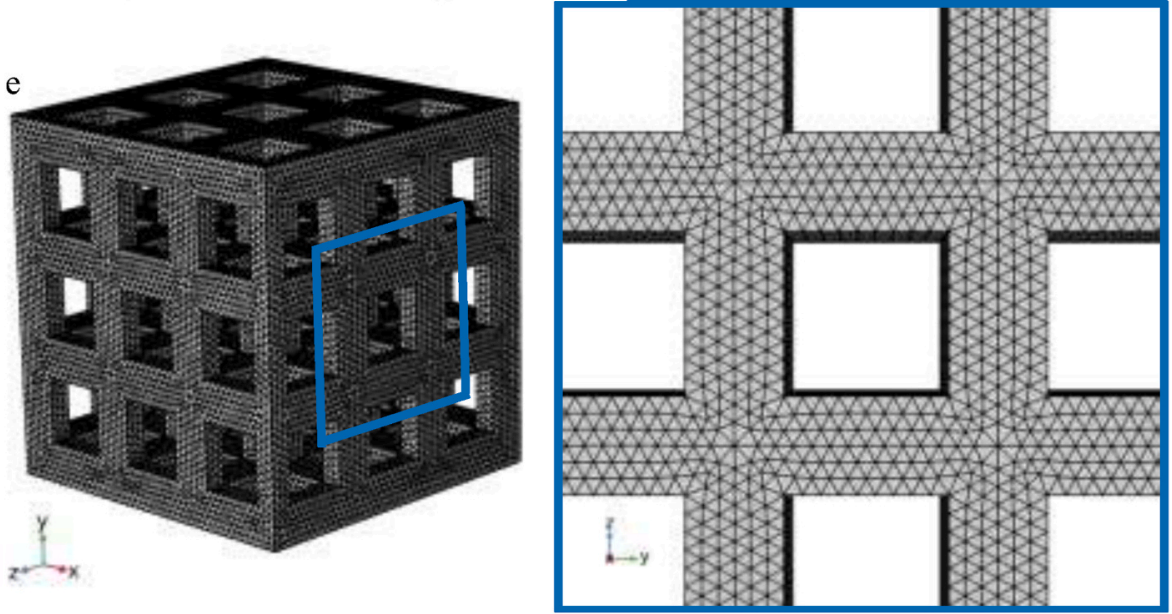

Fig. 4. FEA details of SP1 structure.

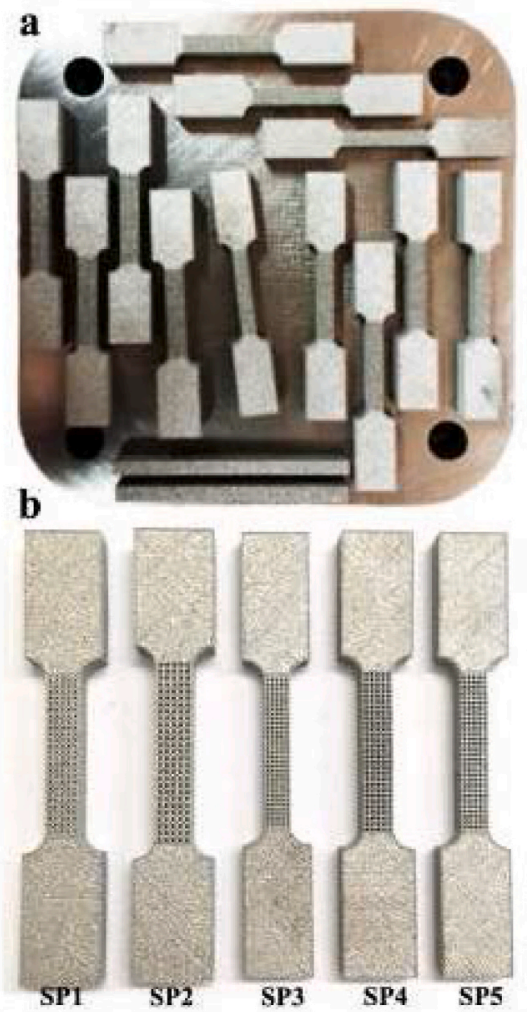

c
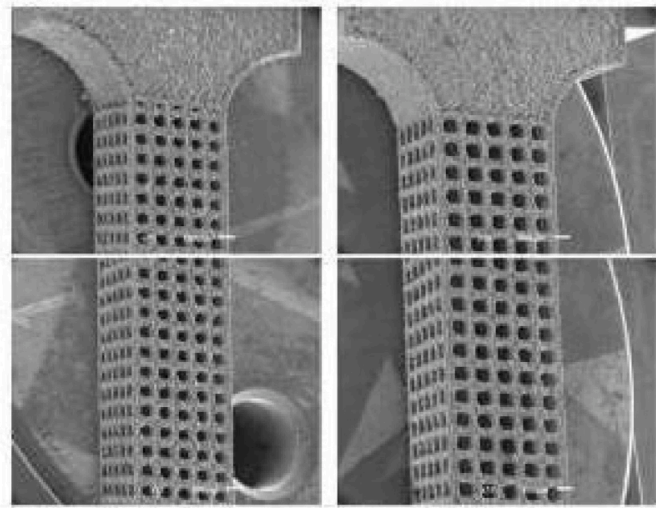

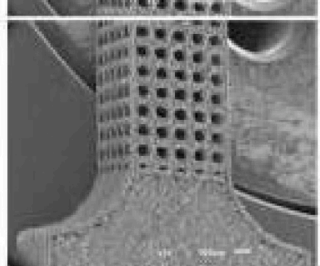

SP3

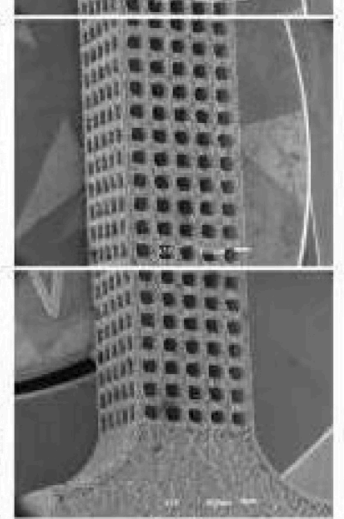

SP5

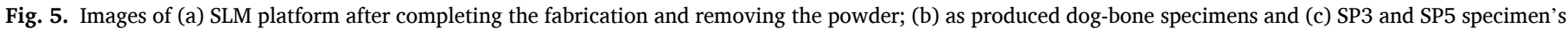
isometric views.

CAD model dimensions, exhibiting high coefficients of determination.

The high coefficients of determination found on linear correlations shown in Figs. 7 and 8 indicate that the differences between the CAD data and the SLM production are systematic and, consequently, these correlations can be considered as design guidelines to fabricate Ti6Al4V SLM structures with desired dimensions. Fig. 9 resumes the porosities of 


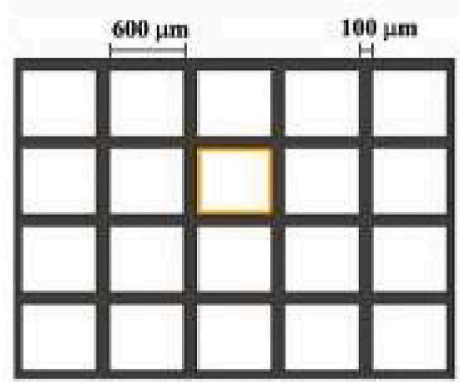

CAD model

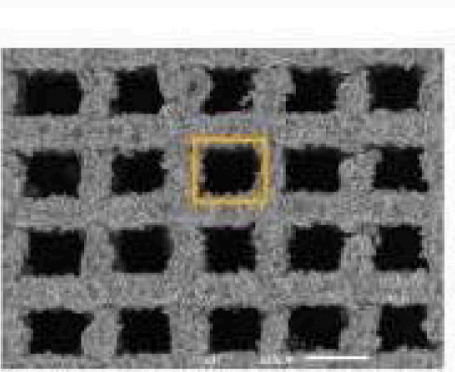

SLM as-produced structure

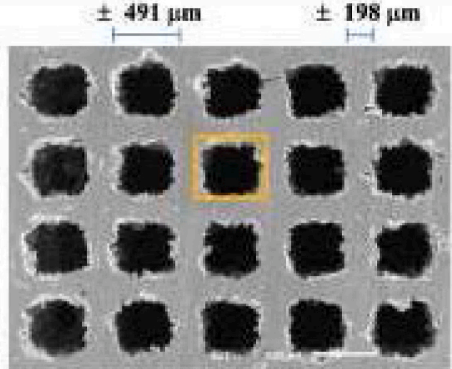

After polishing

Fig. 6. CAD design and SEM images of SP5 structure as-produced and after polishing.

Table 2

Comparison between the model CAD and the produced structures dimensions.

\begin{tabular}{|c|c|c|c|c|c|c|}
\hline \multirow[t]{2}{*}{ Specimen } & \multicolumn{3}{|c|}{ Model CAD data } & \multicolumn{3}{|c|}{$\begin{array}{l}\text { Produced structures } \\
\text { measurements }\end{array}$} \\
\hline & $\begin{array}{l}\text { Open- } \\
\text { cells } \\
\text { size } \\
(\mu \mathrm{m})\end{array}$ & $\begin{array}{l}\text { Walls } \\
\text { size } \\
(\mu \mathrm{m})\end{array}$ & $\begin{array}{l}\text { Porosity } \\
(\%)\end{array}$ & $\begin{array}{l}\text { Open- } \\
\text { cells } \\
\text { size } \\
(\mu \mathrm{m})\end{array}$ & $\begin{array}{l}\text { Walls } \\
\text { size } \\
(\mu \mathrm{m})\end{array}$ & $\begin{array}{l}\text { Porosity } \\
(\%)\end{array}$ \\
\hline SP1 & $\begin{array}{l}500 \\
600\end{array}$ & $\begin{array}{l}300 \\
300\end{array}$ & $\begin{array}{l}64.2 \\
70.3\end{array}$ & $\begin{array}{l}391.3 \pm \\
14\end{array}$ & $\begin{array}{l}391.6 \\
\pm 11\end{array}$ & $\begin{array}{l}45.4 \pm \\
0.4\end{array}$ \\
\hline SP2 & 600 & 300 & 70.3 & $\begin{array}{l}493.4 \pm \\
9\end{array}$ & $\begin{array}{l}405.1 \\
\pm 14\end{array}$ & $\begin{array}{l}53.7 \pm \\
0.8\end{array}$ \\
\hline SP3 & 500 & 150 & 84.0 & $\begin{array}{l}387.8 \pm \\
7\end{array}$ & $\begin{array}{l}247.2 \\
\pm 9\end{array}$ & $\begin{array}{l}64.3 \pm \\
0.3\end{array}$ \\
\hline SP4 & 600 & 150 & 87.6 & $\begin{array}{l}491.3 \pm \\
5\end{array}$ & $\begin{array}{l}251.8 \\
\pm 10\end{array}$ & $\begin{array}{l}70.5 \pm \\
0.6\end{array}$ \\
\hline SP5 & 600 & 100 & 93.3 & $\begin{array}{l}491.8 \pm \\
10\end{array}$ & $\begin{array}{l}198.0 \\
\pm 8\end{array}$ & $\begin{array}{l}78.8 \pm \\
0.2\end{array}$ \\
\hline
\end{tabular}

the models (model CADs and adjusted CADs) used on numerical simulations and also of the Ti6Al4V specimens used on the experimental tests.
Fig. 9 gathers the porosities of the model CAD, the fabricated specimens and the adjusted CAD in which is possible to perceive the systematic differences between the initial CAD and the measured porosity. These differences are consequence of having of thicker walls and smaller open-cells on all of the produced structures when compared to the model CAD as previously mentioned. By analyzing Fig. 9 it is also possible to understand that the adjusted CAD models (obtained based on the morphological characterization of the produced structures) show a porosity similar to the fabricated SLM structures. After understanding these similarities in terms of porosities and architecture, the adjusted CADs were then used to carry out numerical simulations, aiming to determine their elastic modulus and, ultimately, compare with the experimental results. These results can be used to obtain numerical models that correlate the initial CAD dimensions or porosity with the elastic modulus of the effectively fabricated specimens, as shown in Fig. 9.

\subsection{Mechanical characterization}

According to Frost's mechanostat theory, the biological response of bone depends on the level of strain that is induced (Frost, 2003). This aspect has to be considered when designing/producing implant

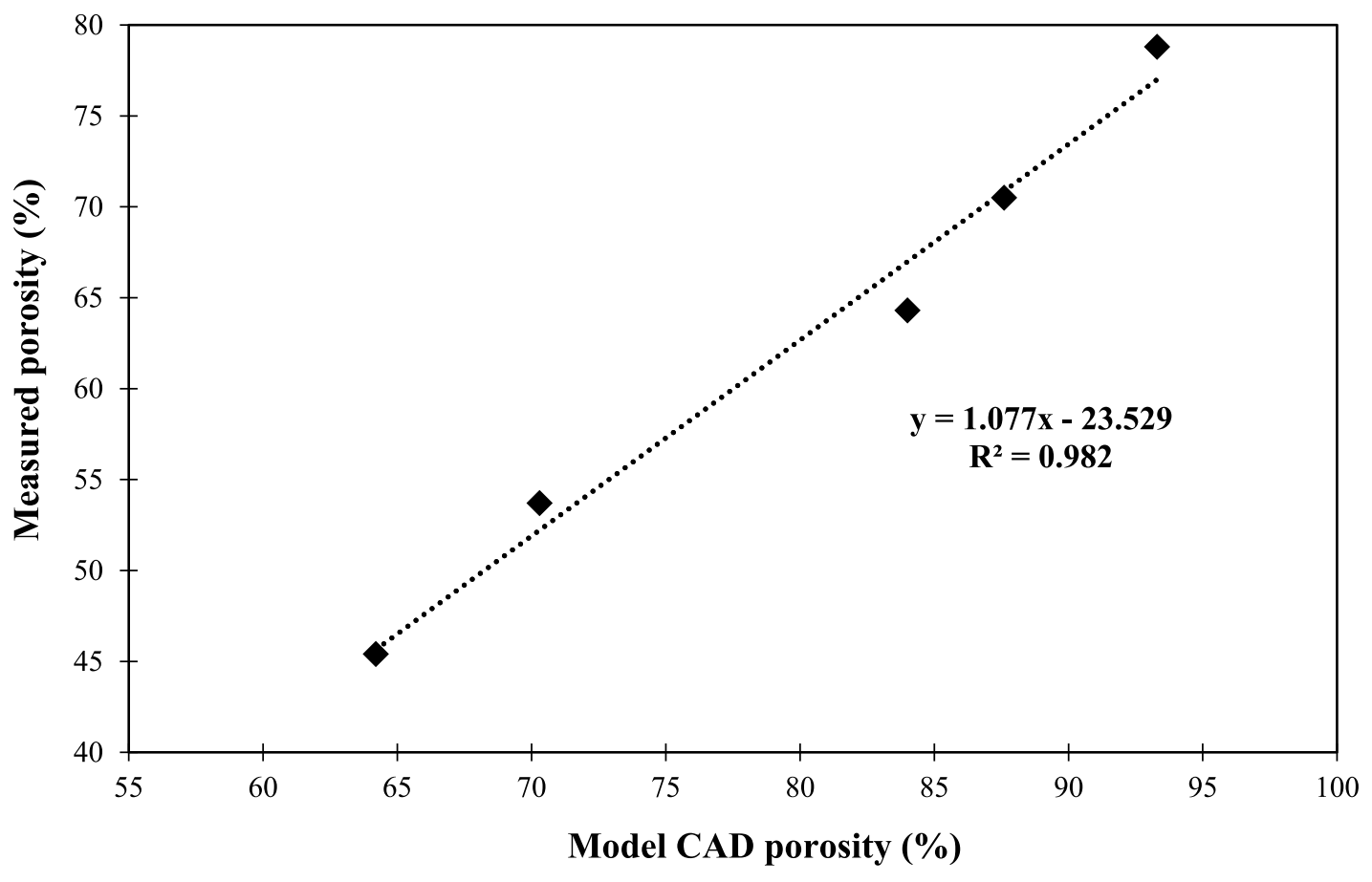

Fig. 7. Linear correlation between the measured porosity and the CAD design porosity. 


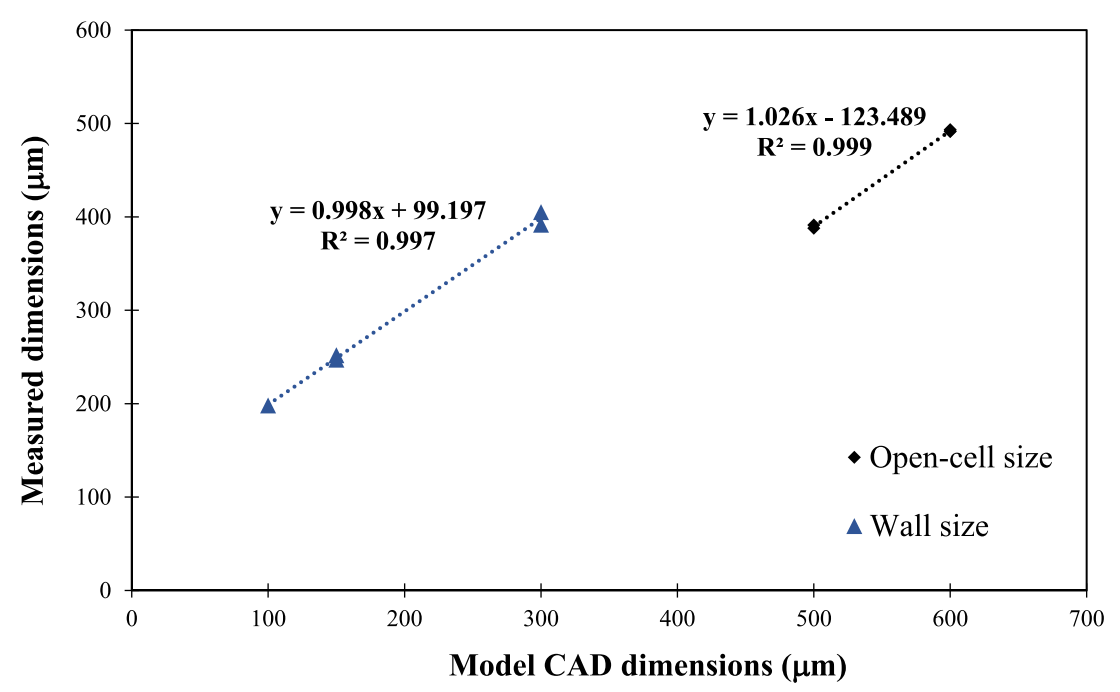

Fig. 8. Linear correlations between the measured dimensions and the model CAD dimensions.

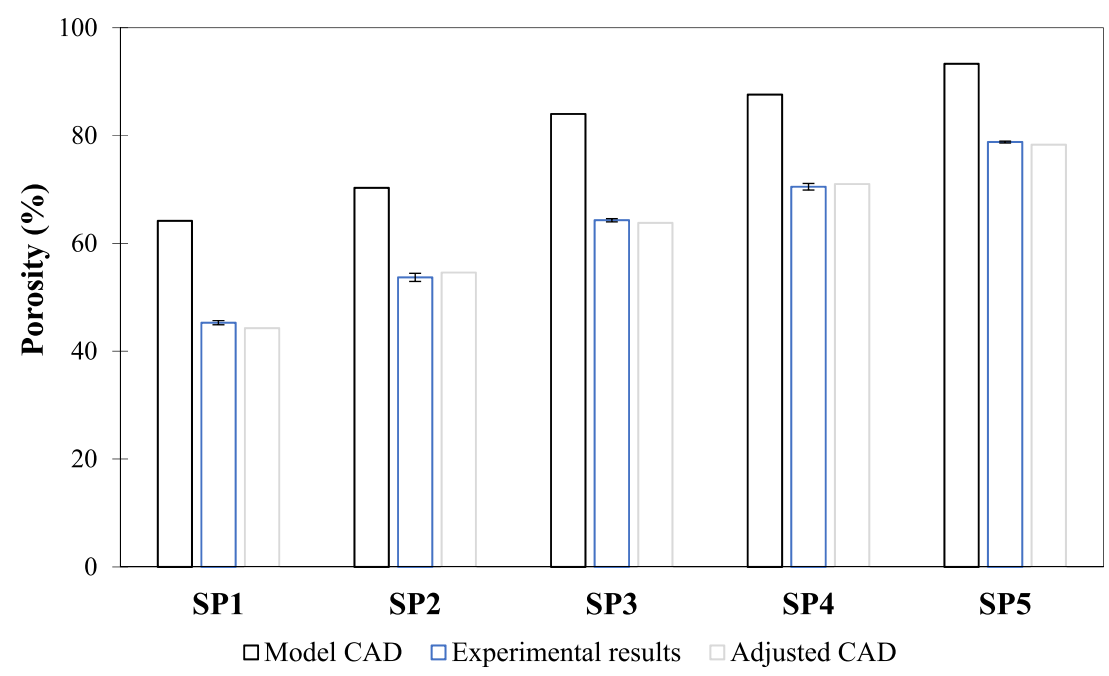

Fig. 9. Porosities of the model CAD, experimental results and adjusted CAD.

materials to avoid the mechanical mismatch between natural bone and dense implant materials. An inefficient and non-uniform stress distribution takes place on the implant-bone interface, which induces stress shielding and can lead to implant failure, typically, 10-20 years after Total Hip arthroplasty (Bagheri et al., 2017; Yan et al., 2012). In this context, the Ti6Al4V cellular structures were mechanically tested

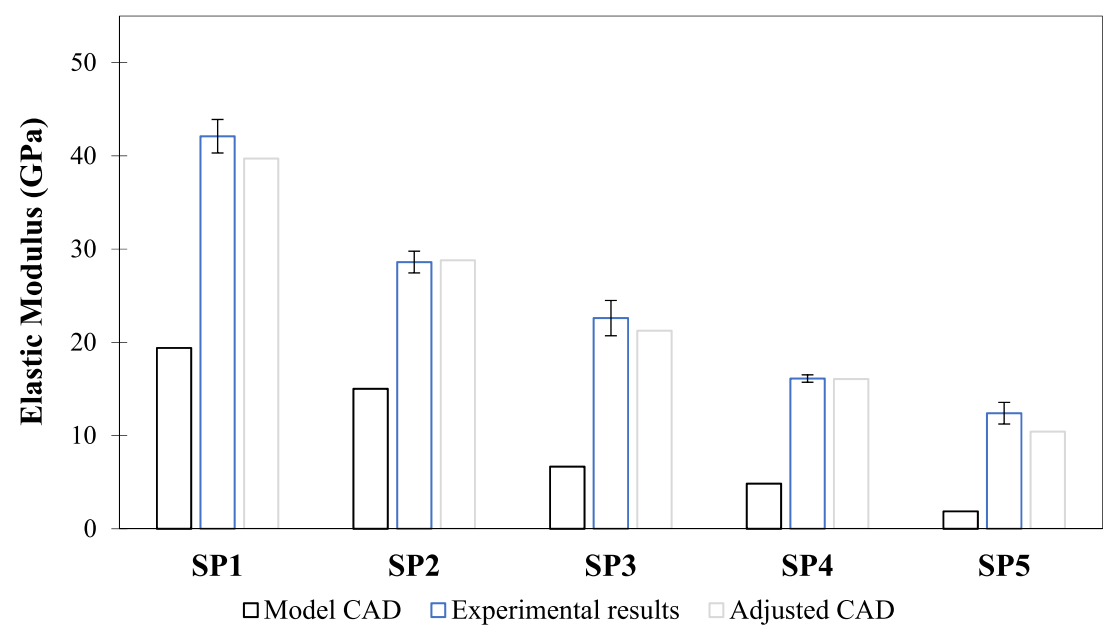

Fig. 10. Experimental and numerical results of the elastic modulus of the Ti6Al4V cellular structures. 
targeting the development of implant solutions. Fig. 10 shows the average elastic modulus results for the different typologies of structures both for experimental and numerical studies.

Firstly, it can be highlighted that four type of Ti6Al4V structures (SP2, SP3, SP4 and SP5) exhibited an average elastic modulus that is within the range of bone tissue, 28.6, 22.6, 16.1 and $12.4 \mathrm{GPa}$, respectively. In fact, several studies report the success of cellular structured materials in reducing bone resorption and stress shielding phenomena through a lower stiffness that matches with cortical bone elastic modulus (10-30 GPa) (Chen et al., 2017; Fousová et al., 2017; Bose et al., 2018; Wang et al., 2016; Geetha et al., 2009; Dallago et al., 2018). Also, these structured materials can be developed to fit each patient by considering tomography or 3D imaging that and then, provide full customized implant solutions such as hip implants (Ryan et al., 2006; Chen and Thouas, 2015; Yan et al., 2015; Thavornyutikarn et al., 2014).

Fig. 10 also shows significant differences when comparing the elastic modulus of the Ti6Al4V structures (tensile testing) and the numerical results obtained using the model CADs. The superior elastic modulus values of the experimental results are explained due to the lower porosity (as consequence of the smaller open-cells and thicker walls) of the SLM produced structures comparing with the model CAD (see Table 2 and Figs. 8 and 9). The SLM structures with lower wall sizes (SP3, SP4 and SP5) exhibit a high difference on the elastic modulus corresponding to 239, 233 and 566\%, when comparing with SP1 (117\%) and SP2 (91\%) structures. This aspect indicates that as lower the sizes of the sub-millimetric structures, as critical the dimensional deviations once SP3, SP4 and SP5 structures exhibited superior differences on the wall sizes, in percentage, when compared with SP1 and SP2. When comparing the experimental results with the numerical simulations of the adjusted CADs, it is visible that the new designs modeled exhibit similar elastic modulus values for all the structures studies (see Figs. 10 and 11).

Fig. 11 shows the correlations between the porosity and the elastic modulus, both for the experimental and numerical studies developed in this study. The power-law correlations show high coefficient of determination $\left(\mathrm{R}^{2}>98 \%\right)$ representing a good fitting for the model CAD, experimental results and adjusted CAD results. It can be mentioned that when considering the power-law correlations for the Gibson and Ashby's model, a good fit was observed and, in some extension, the obtained experimental results are aligned with the predicted models of Gibson and Ashby for porous materials. Also, it was observed that experimental results and adjusted CAD curves are similar and the existing differences can be related with the fillets on the corners of the open-cells of the produced Ti6Al4V cubic-like structures which are induced by the process and also by the spherical powder used on the manufacturing. In fact, when designing and investigating materials for orthopedic application this phenomenon is relevant to avoid regions with high stress concentration, which could lead to crack initiation when exposed to time varying-loads.

The observed differences (open-cell and wall dimensions, porosity and mechanical results) between the CAD designs and the SLM produced structures are relevant and can be used as design standards capable to integrate and anticipate Selective Laser Melting inherent deviations when fabricating Ti6A14V cellular structures (Bartolomeu et al., 2020b, 2020c). By considering this, Ti6Al4V cellular structures that display de intended dimensions, porosity and elastic modulus can be obtained by SLM.

\section{Conclusions}

-Ti6Al4V sub-millimetric cellular structures with different open-cell and wall sizes were designed and produced by SLM;

-Experimental and numerical analyses were performed to obtain the elastic modulus of the Ti6Al4V cubic-like structures;

-Systematic differences were observed when comparing the open-cell and wall sizes of the SLM produced structured and the initial model $\mathrm{CAD}$;

-New CAD models were created to reproduce the real dimensions of the SLM produced structures;. The numerical analyses using the adjusted models showed a good agreement with the experimental tensile tests;

-The Ti6Al4V cellular structures produced by SLM exhibit elastic modulus within a range that match with that of bone tissue, demonstrating that these structures can be used for orthopedic applications;

-The power law correlations obtained exhibiting high coefficient of determination, can be used as design tools to predict and correct the SLM deviations for Ti6Al4V.

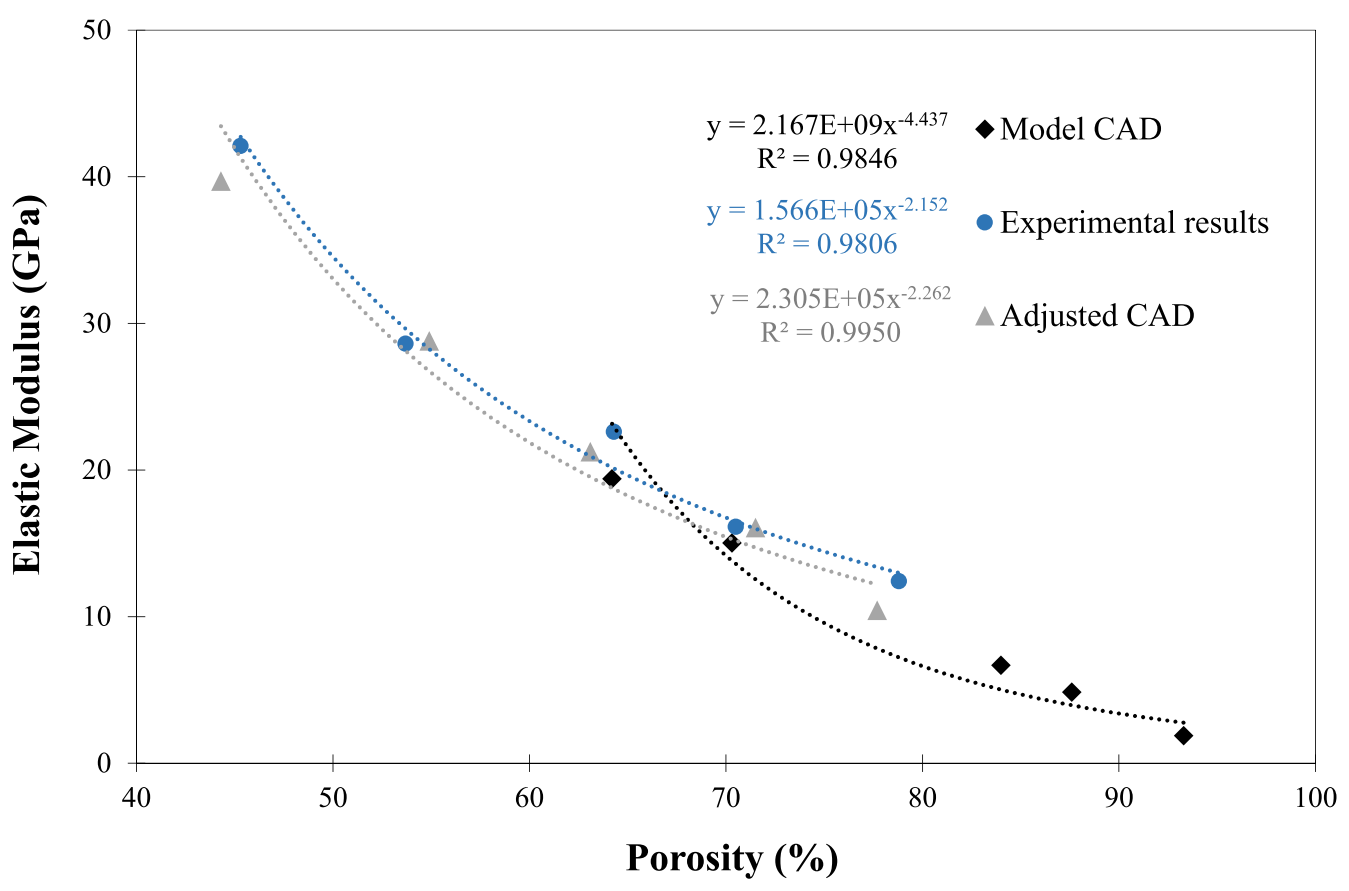

Fig. 11. Relation between the porosity and the elastic modulus for the experimental and numerical studies. 


\section{Author statement}

F. Bartolomeu: Methodology, Validation, Investigation, Writing Original Draft, Writing - Review \& Editing, Visualization. M. M. Costa: Methodology, Investigation, Visualization. N. Alves: Resources, Funding acquisition. G. Miranda: Conceptualization, Investigation, Resources, Writing - Review \& Editing, Supervision, Project administration, Funding acquisition. F. S. Silva: Conceptualization, Resources, Writing - Review \& Editing, Supervision, Project administration, Funding acquisition.

\section{Declaration of competing interest}

The authors declare that they have no known competing financial interests or personal relationships that could have appeared to influence the work reported in this paper.

\section{Acknowledgements}

This work was supported by FCT through the grant SFRH/BD/ $128657 / 2017$ and the projects PTDC/EMS-TEC/5422/2014_ADAPTPROSTHESIS, NORTE-01-0145-FEDER-000018 - HAMaBICo and UID/ EEA/04436/2019.

\section{References}

Arabnejad, S., Johnston, R.B., Ann, J., Singh, B., Tanzer, M., Pasini, D., 2016. Highstrength porous biomaterials for bone replacement : a strategy to assess the interplay between cell morphology, mechanical properties, bone ingrowth and manufacturing constraints. Acta Biomater. 30, 345-356. https://doi.org/10.1016/j actbio.2015.10.048.

Ataee, A., Li, Y., Brandt, M., Wen, C., 2018. Ultrahigh-strength titanium gyroid scaffolds manufactured by selective laser melting (SLM) for bone implant applications. Acta Mater. 158, 354-368. https://doi.org/10.1016/j.actamat.2018.08.005.

Bagheri, Z.S., Melancon, D., Liu, L., Johnston, R.B., Pasini, D., 2017. Compensation strategy to reduce geometry and mechanics mismatches in porous biomaterials built with Selective Laser Melting. J. Mech. Behav. Biomed. Mater. 70, 17-27. https://doi. org/10.1016/j.jmbbm.2016.04.041.

Bartolomeu, F., Faria, S., Carvalho, O., Pinto, E., Alves, N., Silva, F.S., Miranda, G., 2016. Predictive models for physical and mechanical properties of Ti6Al4V produced by Selective Laser Melting. Mater. Sci. Eng. 663, 181-192. https://doi.org/10.1016/j. msea.2016.03.113.

Bartolomeu, F., Buciumeanu, M., Pinto, E., Alves, N., Silva, F.S., Carvalho, O., Miranda, G., 2017a. Wear behavior of Ti6Al4V biomedical alloys processed by selective laser melting, hot pressing and conventional casting. Trans. Nonferrous Met. Soc. China (English Ed.) 27, 829-838. https://doi.org/10.1016/S1003-6326 (17)60060-8.

Bartolomeu, F., Sampaio, M., Carvalho, O., Pinto, E., Alves, N., Gomes, J.R., Silva, F.S., Miranda, G., 2017b. Tribological behavior of Ti6Al4V cellular structures produced by Selective Laser Melting. J. Mech. Behav. Biomed. Mater. 69, 128-134. https:// doi.org/10.1016/j.jmbbm.2017.01.004.

Bartolomeu, F., Abreu, C.S., Moura, C.G., Costa, M.M., Alves, N., Silva, F.S., Miranda, G., 2018a. Ti6Al4V-PEEK multi-material structures - design, fabrication and tribological characterization focused on orthopedic implants. Tribol. Int. 131, 672-678. https:// doi.org/10.1016/j.triboint.2018.11.017.

Bartolomeu, F., Costa, M.M., Gomes, J.R., Alves, N., Abreu, C.S., Silva, F.S., Miranda, G., 2018b. Implant surface design for improved implant stability - a study on Ti6Al4V dense and cellular structures produced by Selective Laser Melting. Tribol. Int. https://doi.org/10.1016/j.triboint.2018.08.012.

Bartolomeu, F., Buciumeanu, M., Costa, M.M., Alves, N., Gasik, M., Silva, F.S., Miranda, G., 2019a. Multi-material Ti6Al4V \& PEEK cellular structures produced by Selective Laser Melting and Hot Pressing : a tribocorrosion study targeting orthopedic applications. J. Mech. Behav. Biomed. Mater. 89, 54-64. https://doi.org/ 10.1016/j.jmbbm.2018.09.009.

Bartolomeu, F., Fonseca, J., Peixinho, N., Alves, N., Gasik, M., Silva, F.S., Miranda, G., 2019b. Predicting the output dimensions, porosity and elastic modulus of additive manufactured biomaterial structures targeting orthopedic implants. J. Mech. Behav. Biomed. Mater. 99 https://doi.org/10.1016/j.jmbbm.2019.07.023.

Bartolomeu, F., Dourado, N., Pereira, F., Alves, N., Miranda, G., Silva, F.S., 2020a. Additive manufactured porous biomaterials targeting orthopedic implants: a suitable combination of mechanical, physical and topological properties. Mater. Sci. Eng. C 107, 110342. https://doi.org/10.1016/j.msec.2019.110342.

Bartolomeu, F., Dourado, N., Pereira, F., Alves, N., Miranda, G., Silva, F.S., 2020b. Additive manufactured porous biomaterials targeting orthopedic implants: a suitable combination of mechanical, physical and topological properties. Mater. Sci. Eng. C 107. https://doi.org/10.1016/j.msec.2019.110342.

Bartolomeu, F., Costa, M.M., Alves, N., Miranda, G., Silva, F.S., 2020c. Engineering the elastic modulus of NiTi cellular structures fabricated by selective laser melting.
J. Mech. Behav. Biomed. Mater. 110, 103891. https://doi.org/10.1016/j. jmbbm.2020.103891.

Bobbert, F.S.L., Lietaert, K., Eftekhari, A.A., Pouran, B., Ahmadi, S.M., Weinans, H., Zadpoor, A.A., 2017. Acta Biomaterialia Additively manufactured metallic porous biomaterials based on minimal surfaces : a unique combination of topological, mechanical , and mass transport properties. Acta Biomater. 53, 572-584. https:// doi.org/10.1016/j.actbio.2017.02.024.

Bose, S., Ke, D., Sahasrabudhe, H., Bandyopadhyay, A., 2018. Progress in materials science additive manufacturing of biomaterials. Prog. Mater. Sci. 93, 45-111. https://doi.org/10.1016/j.pmatsci.2017.08.003.

Buciumeanu, M., Almeida, S., Bartolomeu, F., Costa, M.M., Alves, N., Silva, F.S., Miranda, G., 2018. Ti6Al4V cellular structures impregnated with biomedical PEEK new material design for improved tribological behavior. Tribol. Int. 119, 157-164. https://doi.org/10.1016/j.triboint.2017.10.038.

Cai, C., Gao, X., Teng, Q., Li, M., Pan, K., Song, B., Yan, C., Wei, Q., Shi, Y., 2018. A novel hybrid selective laser melting/hot isostatic pressing of near-net shaped Ti-6Al-4V alloy using an in-situ tooling: interfacial microstructure evolution and enhanced mechanical properties. Mater. Sci. Eng. 717, 95-104. https://doi.org/10.1016/j. msea.2018.01.079.

Capek, J., Machová, M., Fousová, M., Kubbásek, J., Vojtechch, D., Fojt, J., Jablonská, E., Lipov, J., Ruml, T., 2016. Highly porous, low elastic modulus 316L stainless steel scaffold prepared by selective laser melting. Mater. Sci. Eng. C 69, 631-639. https:// doi.org/10.1016/j.msec.2016.07.027.

Chen, Q., Thouas, G.A., 2015. Metallic implant biomaterials. Mater. Sci. Eng. R Rep. 87, 1-57. https://doi.org/10.1016/j.mser.2014.10.001.

Chen, S.Y., Huang, J.C., Pan, C.T., Lin, C.H., Yang, T.L., Huang, Y.S., Ou, C.H., Chen, L.Y., Lin, D.Y., Lin, H.K., Li, T.H., Jang, J.S.C., Yang, C.C., 2017. Microstructure and Mechanical Properties of Open-Cell Porous Ti-6Al- 4V Fabricated by Selective Laser Melting, vol. 713, pp. 248-254. https://doi.org/10.1016/j.jallcom.2017.04.190.

Dallago, M., Fontanari, V., Torresani, E., Leoni, M., Pederzolli, C., Potrich, C., Benedetti, M., 2018. Fatigue and biological properties of Ti-6Al-4V ELI cellular structures with variously arranged cubic cells made by selective laser melting. J. Mech. Behav. Biomed. Mater. 78, 381-394. https://doi.org/10.1016/j. jmbbm.2017.11.044.

Dallago, M., Winiarski, B., Zanini, F., Carmignato, S., Benedetti, M., 2019a. On the effect of geometrical imperfections and defects on the fatigue strength of cellular lattice structures additively manufactured via Selective Laser Melting. Int. J. Fatig. 124, 348-360. https://doi.org/10.1016/j.ijfatigue.2019.03.019.

Dallago, M., Raghavendra, S., Luchin, V., Zappini, G., Pasini, D., Benedetti, M., 2019b. Geometric assessment of lattice materials built via Selective Laser Melting. Mater. Today Proc. 7, 353-361. https://doi.org/10.1016/j.matpr.2018.11.096.

Dias, M.R., Guedes, J.M., Flanagan, C.L., Hollister, S.J., Fernandes, P.R., 2014. Medical Engineering \& Physics Optimization of scaffold design for bone tissue engineering. Comput. Exp. Stud. 36, 448-457.

Fousová, M., Vojt, D., Jablonská, E., Fojt, J., 2017. Characteristics of gradient porosity Ti6Al-4V alloy prepared by SLM process. J. Mech. Behav. Biomed. Mater. Promis. 69, 368-376. https://doi.org/10.1016/j.jmbbm.2017.01.043.

Frost A, H.M., 2003. Update of bone physiology and Wolff s law for clinicians. Angle Orthod. 74, 3-15, 2004.

Geetha, M., Singh, A.K., Asokamani, R., Gogia, A.K., 2009. Ti based biomaterials, the ultimate choice for orthopaedic implants - a review. Prog. Mater. Sci. 54, 397-425. https://doi.org/10.1016/j.pmatsci.2008.06.004.

Holzwarth, U., Cotogno, G., 2012. Total Hip Arthroplasty. https://doi.org/10.2788/ 31286.

Huang, S., Sing, S.L., de Looze, G., Wilson, R., Yeong, W.Y., 2020. Laser powder bed fusion of titanium-tantalum alloys: compositions and designs for biomedical applications. J. Mech. Behav. Biomed. Mater. 108, 103775. https://doi.org/ 10.1016/j.jmbbm.2020.103775.

Karageorgiou, V., Kaplan, D., 2005. Porosity of 3D biomaterial scaffolds and osteogenesis. Biomaterials 26, 5474-5491. https://doi.org/10.1016/j. biomaterials.2005.02.002.

Kumar, A., Mandal, S., Barui, S., Vasireddi, R., Gbureck, U., Gelinsky, M., Basu, B., 2016. Low temperature additive manufacturing of three dimensional scaffolds for bonetissue engineering applications: processing related challenges and property assessment. Mater. Sci. Eng. R Rep. 103, 1-39. https://doi.org/10.1016/j. mser.2016.01.001.

Moura, C.G., Carvalho, O., V Gonçalves, L.M., Cerqueira, M.F., Nascimento, R., Silva, F., 2019. Materials Science \& Engineering C Laser surface texturing of Ti-6Al-4V by nanosecond laser : surface characterization, Ti-oxide layer analysis and its electrical insulation performance. Mater. Sci. Eng. C 104, 109901. https://doi.org/10.1016/j. msec.2019.109901.

Moura, C.G., Carvalho, O., Magalhães, V.H., Pereira, R.S.F., Cerqueira, M.F., Gonçalves, L.M.V., Nascimento, R.M., Silva, F.S., 2020. Laser printing of microelectronic communication systems for smart implants applications. Optic Laser. Technol. 128, 106211. https://doi.org/10.1016/j.optlastec.2020.106211.

Ran, Q., Yang, W., Hu, Y., Shen, X., Yu, Y., Xiang, Y., Cai, K., 2018. Osteogenesis of 3D printed porous Ti6Al4V implants with different pore sizes. J. Mech. Behav. Biomed. Mater. 84, 1-11. https://doi.org/10.1016/j.jmbbm.2018.04.010.

Rotta, G., Seramak, T., 2015. Estimation of Young's Modulus of the Porous Titanium Alloy with the Use of Fem Package. https://doi.org/10.1515/adms-2015-0020.

Ryan, G., Pandit, A., Apatsidis, D.P., 2006. Fabrication methods of porous metals for use in orthopaedic applications. Biomaterials 27, 2651-2670. https://doi.org/10.1016/ j.biomaterials.2005.12.002.

Sing, S.L., Wiria, F.E., Yeong, W.Y., 2018. Selective laser melting of lattice structures: a statistical approach to manufacturability and mechanical behavior. Robot. Comput. Integrated Manuf. 49, 170-180. https://doi.org/10.1016/j.rcim.2017.06.006. 
Thavornyutikarn, B., Chantarapanich, N., Chen, Q., 2014. Bone Tissue Engineering Scaffolding : Computer-Aided Scaffolding Techniques. https://doi.org/10.1007/ s40204-014-0026-7.

Tong, J., Bowen, C.R., Persson, J., Plummer, A., 2016. Mechanical properties of titaniumbased Ti-6Al-4V alloys manufactured by powder bed additive manufacture. Mater. Sci. Technol., 0836 https://doi.org/10.1080/02670836.2016.1172787.

Van Bael, S., Kerckhofs, G., Moesen, M., Pyka, G., Schrooten, J., Kruth, J.P., 2011. MicroCT-based improvement of geometrical and mechanical controllability of selective laser melted Ti6Al4V porous structures. Mater. Sci. Eng. 528, 7423-7431. https:// doi.org/10.1016/j.msea.2011.06.045.

Van Hooreweder, B., Apers, Y., Lietaert, K., Kruth, J.P., 2017. Improving the fatigue performance of porous metallic biomaterials produced by Selective Laser Melting. Acta Biomater. 47, 193-202. https://doi.org/10.1016/j.actbio.2016.10.005.

Wally, Z.J., Haque, A.M., Feteira, A., Claeyssens, F., Goodall, R., Reilly, G.C., 2019. Journal of the Mechanical Behavior of Biomedical Materials Selective laser melting processed Ti6Al4V lattices with graded porosities for dental applications. J. Mech. Behav. Biomed. Mater. 90, 20-29. https://doi.org/10.1016/j.jmbbm.2018.08.047.
Wang, X., Xu, S., Zhou, S., Xu, W., Leary, M., Choong, P., Qian, M., Brandt, M., Xie, Y.M., 2016. Topological design and additive manufacturing of porous metals for bone scaffolds and orthopaedic implants: a review. Biomaterials 83, 127-141. https://doi. org/10.1016/j.biomaterials.2016.01.012.

Weißmann, V., Bader, R., Hansmann, H., Laufer, N., 2016. Influence of the structural orientation on the mechanical properties of selective laser melted Ti6Al4V openporous scaffolds. Mater. Des. 95, 188-197. https://doi.org/10.1016/j. matdes.2016.01.095.

Wittenberg, R.H., Steffen, R., Windhagen, H., Bücking, P., Wilcke, A., 2013. Five-year results of a cementless short-hip-stem prosthesis. Orthop. Rev. 5, e4. https://doi.org/ 10.4081/or.2013.e4.

Yan, C., Hao, L., Hussein, A., Raymont, D., 2012. Int. J. Mach. Tools. Manuf. Eval. Cell. Latt. Struct. Manuf. Using Sel. Laser. Melt. 62, 32-38. https://doi.org/10.1016/j. ijmachtools.2012.06.002.

Yan, C., Hao, L., Hussein, A., Young, P., 2015. Ti-6Al-4V triply periodic minimal surface structures for bone implants fabricated via selective laser melting. J. Mech. Behav. Biomed. Mater. 51, 61-73. https://doi.org/10.1016/j.jmbbm.2015.06.024. 